\title{
Disordered left ventricular contraction associated with abnormalities of conduction: an echocardiographic study
}

\author{
D. G. GiBSON
}

A PATIENT with cardiomyopathy often presents with evidence of heart failure in the absence of apparent underlying cause. This clinical picture usually results from disease of the heart muscle itself, but the rossibility exists that it might also be due to impairment of the action of structurally and functionally normal myocardium by inco-ordinated ventricular contraction. The development of echocardiography has provided a non-invasive method of studying left ventricular contraction, allowing frequent records to be made rapidly and painlessly without hazard to the patient. The pattern of contraction is characterized from records showing echoes from the interventricular septum and posterior wall in a region just below the mitral valve. The normal position and movement of these two structures are shown in Fig. 1. During ventricular systole the dominant movement of the interventricular septum is in a posterior direction, while the posterior wall moves forwards as the transverse diameter of the cavity is reduced. During diastole, the two echoes move in the reverse direction, rapidly at first and then more slowly in the period of diastasis. This pattern of movement has been taken to represent a co-ordinated ventricular contraction and is that commonly seen, even in the presence of considerable cavity dilatation or ventricular hypertrophy.

Abnormalities of septal movement have previously been described in association with atrial septal defect and are probably related to the increase in right ventricular stroke volume that occurs in this condition (Diamond et al., 1971). In the majority of these patients septal movement is the reverse of normal, being in an anterior direction during systole while in the remainder it undergoes a series of movements of low amplitude, with no dominant displacement in either direction. Similar abnormalities of septal movement may occur in association with acquired pulmonary hypertension or tricuspid regurgitation due, for example, to rheumatic mitral valve disease, when the relative loads on the right and left ventricles are altered.

In the present study, echocardiography was used to define the effects of abnormalities of ventricular activation on the pattern of contraction. Eight patients with classical left bundle branch block were studied, in whom the duration of the QRS complex

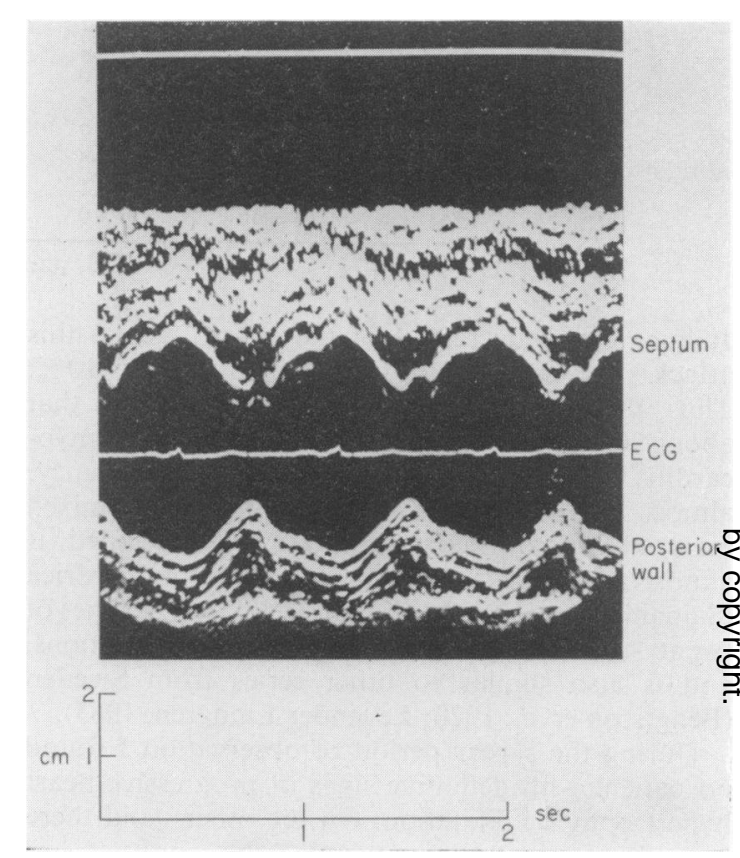

FIG. 1. Echocardiogram showing the left ventricular cavity in a patient with normal activation. During systole the dominant movement of the septum is in a posterior direction, while the posterior wall of the left ventricle moves forward. In this, and all other echocardiograms, the anterior chest wall is at the top, the depth markers represent distances of $1 \mathrm{~cm}$ and the time markers intervals of $0.5 \mathrm{sec}$.

was more than $0.12 \mathrm{sec}$ and in whom septal Q waves were absent. In four the abnormality was due to ischaemic heart disease, in two it was associated with rheumatic heart disease and in two it first appeared after cardiac surgery, aortic valve replacement in one and myotomy for hypertrophic cardiomyopathy in the other.

With the transducer in the fourth left interspace, the echo from the anterior cusp of the mitral valve was first identified and then the beam was directed a little more laterally and inferiorly so that the echoes from the septum and posterior wall were demonstrated simultaneously. The septum was identified as a double echo anterior to that originating 
from the anterior cusp of the mitral valve, and the posterior wall as a band of echoes behind the mitral valve, showing a dominant forward movement during systole (Popp et al., 1969; Chapelle \& Mensch, 1969). In all cases a simultaneous ECG was also recorded.

In all patients septal movement was abnormal. Instead of the dominant posterior movement during ventricular systole it was in an anterior direction, i.e. parallel to that of the posterior wall, while during diastole movement was in a posterior direction (Figs. 2 and 3). In one patient with intermittent left bundle branch block (Fig. 4) this pattern was only seen in the beats with delayed activation, normal beats being associated with normal septal movement. This abnormality did not appear to be associated with left ventricular cavity size, which ranged from 120 to $480 \mathrm{ml}$ as calculated from the cube of the internal dimension, and, although sought specifically, was not found in any of fifty patients studied by echocardiography and biplane angiography in whom ventricular activation was normal. Attempts to reproduce it by manipulation of transducer position were also unsuccessful. It is possible that localized disease of the septum was responsible, in some patients, for abnormalities of both conduction and movement, although this explanation is unlikely in the patient with intermittent left bundle branch

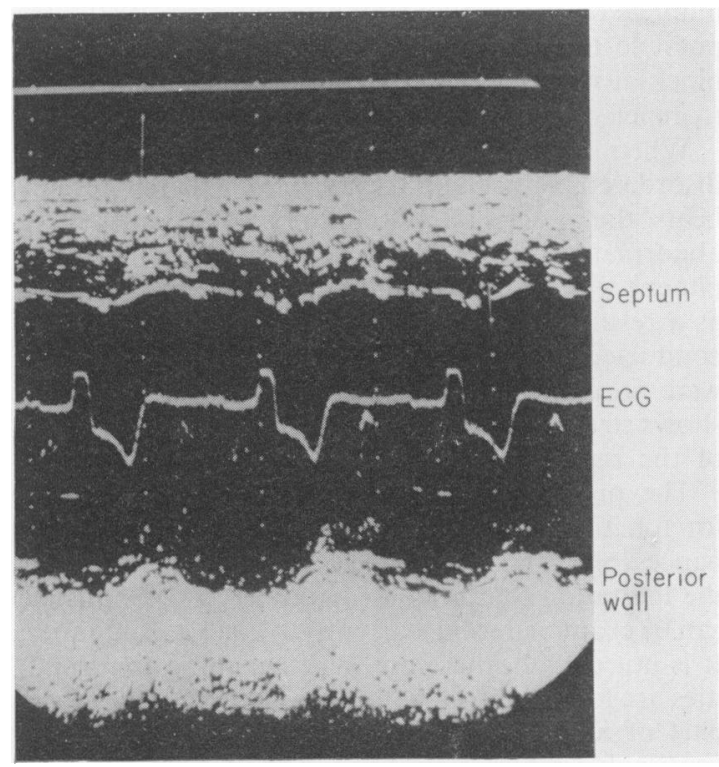

FIG. 2. Echocardiogram of a patient with mitral valve disease and left bundle branch block. Posterior wall movement is normal but the septum moves paradoxically during systole, its dominant movement being forwards rather than backwards. The left ventricular cavity is greatly enlarged.

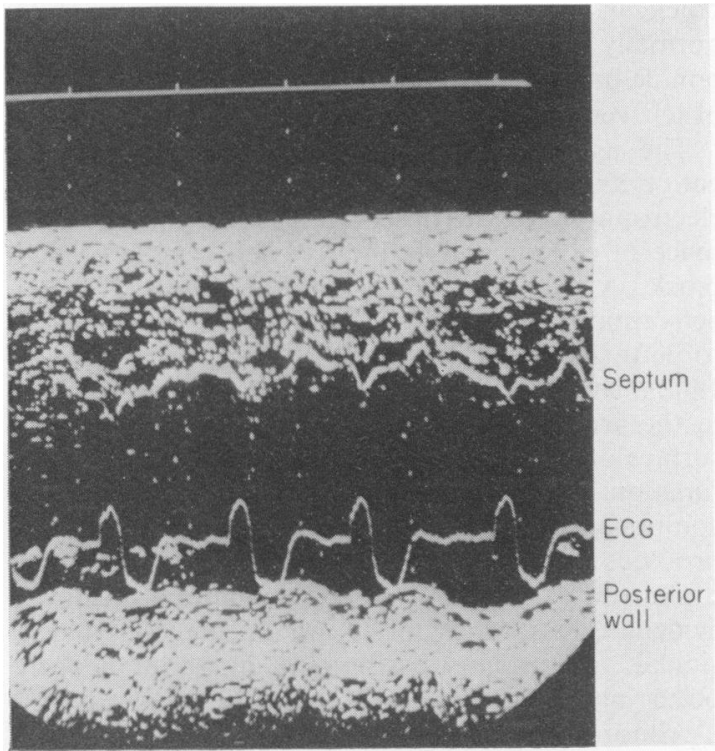

FIG. 3. Echocardiogram of a patient with left bundle branch block, probably due to ischaemic heart disease. Septal movement is in an anterior direction during systole.

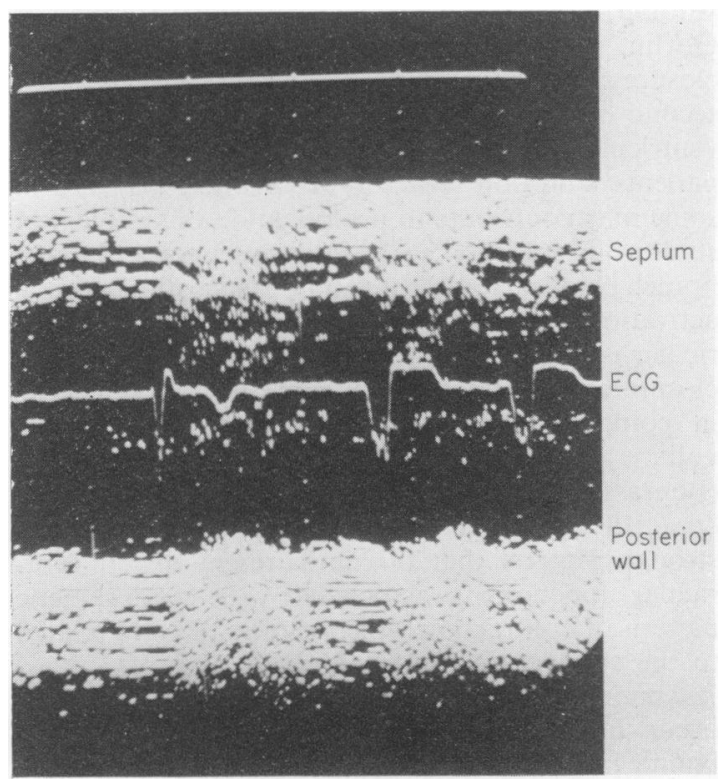

FIG. 4. Echocardiogram of a patient with intermittent left bundle branch block. The septum moves normally during systole after the normally conducted beat, but paradoxically after the two beats showing left bundle branch block. 
block in whom septal movement was normal in normally conducted beats, suggesting that left bundle branch block, per se, can cause abnormalities of left ventricular contraction.

The association between abnormalities of activation and contraction is explicable on the basis of electrophysiological observations made in the presence of experimentally induced left bundle branch block in the dog, when the direction of septal activation is the reverse of normal, being from right to left (Rodriguez \& Sodi-Pallares, 1952; Scott, 1962). This is associated with a delay of $50-80 \mathrm{msec}$ in the arrival of the impulse at the left ventricular surface of the septum, which has been ascribed to a functional block between its right and left ventricular components. Activation in the free wall, however, proceeds normally, thus explaining the resultant dyskinetic contraction. Although there is no direct evidence, loss of septal $Q$ waves suggests that a similar abnormality is present in spontaneously occurring left bundle branch block in man.

Abnormalities of left ventricular contraction have previously been described as occuring in the majority of patients with left bundle branch block. Although the normal relationship between the onset of right and left ventricular contraction is maintained (Braunwald \& Morrow, 1957), left ventricular systole is prolonged in left bundle branch block (Segers \& Hendrick, 1957; Lev, 1961; Baragan et al., 1968; Adolph, Fowler \& Tanaka, 1969; Haft, Herman \& Gorlin, 1971), resulting in delay in aortic valve closure and in reversal of the normal splitting of the second heart sound (Haber \& Leatham, 1965). Left ventricular disease is frequently present in such patients (Johnson et al., 1951; Scott, 1965) and in some may contribute to prolongation of systole, but studies in patients with intermittent left bundle branch block have indicated that beats with abnormal activation are associated with prolonged left ventricular isovolumic contraction, delay in mitral valve closure and increased left ventricular ejection time in comparison with normal beats, while stroke volume and peak left ventricular pressure are reduced (Bourassa, Boiteau \& Allenstein, 1962; Baragan et al., 1968; Adolph et al., 1969). The present results strongly suggest that this impairment of left ventricular function is associated with a dyskinetic pattern of contraction which can be directly related to the conduction disturbance.

Abnormal left ventricular contraction may also occur in the presence of surgically induced left bundle branch block. Figure 5 is the echocardiogram from a patient with hypertrophic cardiomyopathy showing abnormal septal movement in whom the conduction disturbance originated at the time of left ventricular myotomy. Since the pressure gradient between the left ventricular cavity and the aorta in

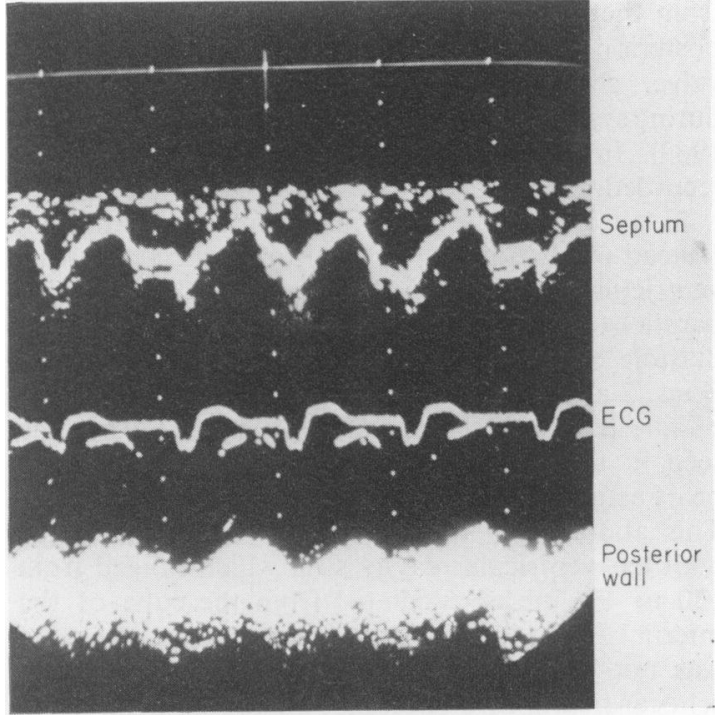

Fig. 5. Echocardiogram of a patient with hypertrophic cardiomyopathy, with left bundle branch block which developed at the time of ventricular myotomy. There is obvious paradoxical movement of the septum during systole.

this condition is due to forward movement of the anterior cusp of the mitral valve during systole to impinge on the septum (Popp \& Harrison, 1969), it is possible that the production of left bundle branch block at the time of operation may itself contribute to relief of the stenosis.

When left ventricular activation is even more disordered, as in the presence of ventricular ectopic beats, the pattern of contraction also becomes more abnormal. Figure 6 is an echocardiogram from a patient with mitral valve disease, who was coupling as a result of digitalis intoxication. In the normally conducted beats septal and posterior wall movement were normal, while in the ectopic beats the septum shows striking paradoxical movement into the cavity of the right ventricle.

The present results suggest an anatomical basis for functional abnormalities associated with disturbances of ventricular activation, but are subject to the limitation that only a small part of the ventricle can be examined using currently available techniques. It is not certain, therefore, whether these abnormalities are localized to the septum or whether they form part of a more generalized disorganization of left ventricular contraction. Even in the former case, the degree of paradoxical movement might be expected, of itself, to cause appreciable interference with left ventricular function, whose clinical consequences will clearly depend on the ability of the remainder of the ventricle to compensate and which, in the 


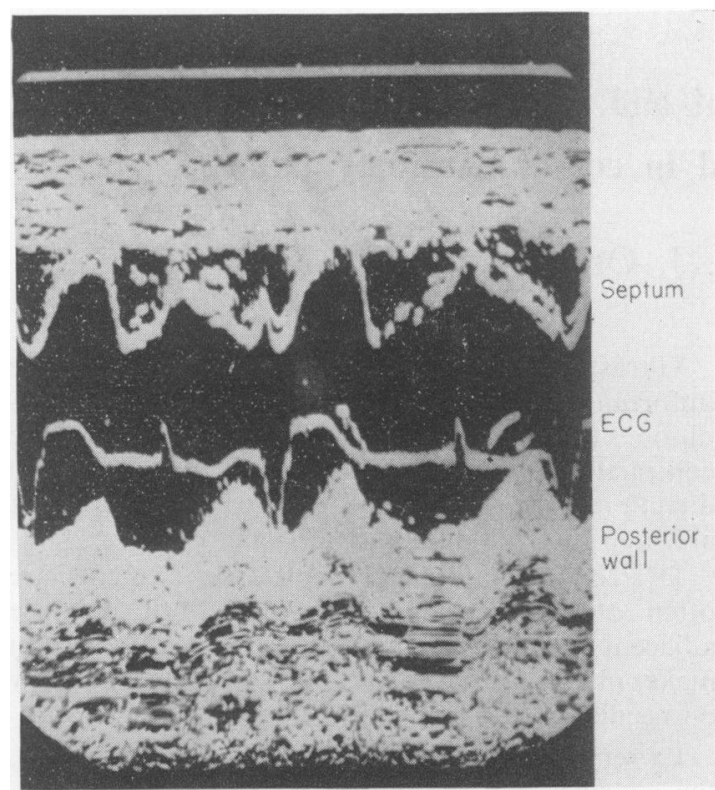

FIG. 6. Echocardiogram from a patient with mitral valve disease and coupling due to digitalis intoxication. Septal movement is normal in the beats with normal ventricular activation, but is paradoxical in the ectopic beats. The right ventricular cavity is enlarged due to pulmonary hypertension.

presence of severe disease, might further compromise cardiac action. Conduction disturbances are common in ischaemic heart disease or cardiomyopathy and in these conditions ventricular function would be particularly impaired by inco-ordinated contraction.

The present results also stress that certain current methods of assessing left ventricular function give an incomplete picture of the overall disturbance in the presence of regional abnormalities of left ventricular contraction. In the patient whose echocardiogram is illustrated in Fig. 6, for example, posterior wall velocity, which has been proposed as a measure of 'contractility' (Krauntz \& Kennedy, 1970; Wharton, Smithen \& Sowton, 1972), is normal in the ectopic beats, although end-diastolic volume is somewhat reduced, suggesting the erroneous conclusion that left ventricular function had actually improved. For the same beats, a catheter tip manometer would have recorded a reduced developed pressure and rate of rise of pressure, while an electromagnetic flowmeter catheter in the ascending aorta would have shown no signal at all if the aortic valve had failed to open. Using three different methods, therefore, left ventricular function in the ectopic beats might be shown to be improved, reduced or absent in comparison with the normally conducted ones, suggesting that in the presence of such regional abnormalities left ventricular function cannot satisfactorily be described in terms of a single scalar parameter.

\section{References}

AdolPh, R.J., Fowler, N.O. \& TAnaKA, K. (1969) Prolongation of isovolumic contraction time in LBBB. American Heart Journal, 78, 585.

Baragan, J., Fernandez-Canmano, F., Coblence, B. \& LENÈGRE, J. (1967) Intermittent complete left bundle branch block: phonocardiographic and mechanocardiographic study of one case. British Heart Journal 29, 520.

Baragan, J., Fernandez-CaAmano, F., Sozutek, Y., Coblence, B. \& Lenegre, J. (1968) Chronic left complete bundle-branch block: phonocardiographic and mechanocardiographic study of thirty cases. British Heart Journal, 30, 196.

Bourassa, M.G., Boiteau, G.M. \& Allenstein, B.J. (1962) Hemodynamic studies during intermittent left bundle branch block. American Journal of Cardiology, 10, 792.

Braunwald, E. \& Morrow, A.G. (1957) Sequence of ventricular contraction in human bundle branch block. A study based on simultaneous catheterization of both ventricles American Journal of Medicine, 23, 205.

Chapelle, M. \& Mensch, B. (1969) Etude des variations du diamètre ventriculaire gauche chez l'homme par échocardiographie transthoracique. Archives des maladies du coeur et des vaisseaux, 62, 1505.

Diamond, M.A., Dillon, J.C., Haine, C.L., Chang, S. \& Feigenbaum, H. (1971) Echocardiographic features of atrial septal defect. Circulation, 43, 129.

Haber, E. \& Leatham, A. (1965) Splitting of the heart sounds from ventricular asynchrony in bundle-branch block, ventricular ectoptic beats, and artificial pacing. British Heart Journal, 27, 691.

Haft, J.I., Herman, M.V. \& Gorlin, R. (1971) Left bundle branch block. Etiologic, hemodynamic and ventriculographic considerations. Circulation, 43, 279.

Johnson, R.P., Messer, A.L., Shreenivas, S.E. \& White, P.D. (1951) Prognosis in bundle branch block. II. Factors influencing the survival period in left bundle branch block. American Heart Journal, 41, 225.

KRAUNTZ, R.F. \& KenNedy, J.W. (1970) Ultrasonic determination of left ventricular wall motion in normal man. American Heart Journal, 79, 36.

LEv, M. (1961) Complete left bundle branch block. A physiologic-pathologic correlation. American Heart Journal 61, 149.

PopP, R.L. \& Harrison, D.C. (1969) Ultrasound in the diagnosis and evaluation of therapy of idiopathic hypertrophic subaortic stenosis. Circulation, 40, 905.

Popp, R.L., Wolfe, S.B., Hirata, T. \& Feigenbaum, H. (1969) Estimation of right and left ventricular size by ultrasound. A study of the echoes from the interventricular septum. American Journal of Cardiology, 24, 523.

Rodriguez, M.I. \& Sodi-Pallares, D. (1952) The mechanism of complete and incomplete bundle branch block. American Heart Journal, 44, 715.

Scotr, R.C. (1962) Current concepts of ventricular activation in the normal heart, in left bundle branch block and in left bundle branch block with myocardial infarction. American Heart Journal 64, 696.

ScotT, R.C. (1965) Left bundle branch block - a clinical assessment. American Heart Journal, 70, 535.

Segers, S. \& Hendrick, J. (1957) Etude electrokymographique de delai d'éjection dans les blocs intraventriculaires. Acta cardiologica, 6, 150.

Wharton, C.F.P., Smithen, C.S. \& Sowton, E. (1971) Changes in left ventricular wall movement after acute myocardial infarction measured by reflected ultrasound. British Medical Journal, 4, 75. 